\title{
Identifying Loci Conferring Resistance to Leaf and Stripe Rusts in a Spring Wheat Population (Triticum aestivum) via Genome-Wide Association Mapping
}

\author{
Weizhen Liu, ${ }^{1,2}$ James Kolmer,,34 Sheri Rynearson, ${ }^{2}$ Xianming Chen,5,6 Liangliang Gao,, ${ }^{7,8}$ James A. Anderson, ${ }^{7}$ \\ M. Kathryn Turner, 7,9 and Michael Pumphrey ${ }^{2, \dagger}$ \\ ${ }^{1}$ School of Computer Science and Technology, Wuhan University of Technology, Wuhan, Hubei 430070, China \\ ${ }^{2}$ Department of Crop and Soil Sciences, Washington State University, Pullman, WA 99164-6430, U.S.A. \\ ${ }^{3}$ Cereal Disease Laboratory, U.S. Department of Agriculture Agricultural Research Service, St. Paul, MN 55108, U.S.A. \\ ${ }^{4}$ Department of Plant Pathology, University of Minnesota, St. Paul, MN 55018, U.S.A. \\ ${ }^{5}$ Wheat Health, Genetics, and Quality Research Unit, U.S. Department of Agriculture Agricultural Research Service, Pullman, WA 99164- \\ 6430, U.S.A. \\ ${ }^{6}$ Department of Plant Pathology, Washington State University, Pullman, WA 99164-6430, U.S.A. \\ ${ }^{7}$ Department of Agronomy and Plant Genetics, University of Minnesota, St. Paul, MN 55108, U.S.A. \\ ${ }^{8}$ Department of Plant Pathology, Kansas State University, Manhattan, KS 66502, U.S.A. \\ ${ }^{9}$ The Land Institute, Salina, KS 67401, U.S.A. \\ Accepted for publication 30 June 2019.
}

\begin{abstract}
A previous genome-wide association study (GWAS) for leaf rust (caused by Puccinia triticina) resistance identified 46 resistance quantitative trait loci (QTL) in an elite spring wheat leaf rust resistance diversity panel. With the aim of characterizing the pleiotropic resistance sources to both leaf rust and stripe rust (caused by $P$. striiformis $\mathrm{f}$. sp. tritici), stripe rust responses were tested in five U.S. environments at the adult-plant stage and to five U.S. races at the seedling stage. The data revealed balanced phenotypic distributions in this population except for the seedling response to $P$. striiformis f. sp. tritici race PSTv-37. GWAS for stripe rust resistance discovered a total of 21 QTL significantly associated with all-stage or field resistance on chromosomes 1B, 1D, 2B,

3B, 4A, 5A, 5B, 5D, 6A, 6B, 7A, and 7B. Previously documented pleiotropic resistance genes $\mathrm{Yr} 18 / \mathrm{Lr} 34$ and $\mathrm{Yr} 46 / \mathrm{Lr} 67$ and tightly linked genes $Y r 17-L r 37$ and $Y r 30-S r 2-L r 27$ were also detected in this population. In addition, stripe rust resistance QTL Yrswp-2B.1, Yrswp-3B, and Yrswp-7B colocated with leaf rust resistance loci $2 B \quad 3,3 B t 2$, and $7 B \quad 4$, respectively. Haplotype analysis uncovered that $\operatorname{Yrswp}-3 B$ and $3 B_{-} t 2$ were either tightly linked genes or the same gene for resistance to both stripe and leaf rusts. Single nucleotide polymorphism markers IWB35950, $I W B 74350$, and $I W B 72134$ for the 3B QTL conferring resistance to both rusts should be useful in incorporating the resistance allele(s) in new cultivars.
\end{abstract}

Wheat (Triticum spp.) is one of the three major staple cereal crops in the world, together with rice and maize, and ranks first as a protein source. Wheat is the most important food crop in North Africa and West and Central Asia, where it supplies half of the total calories consumed in these areas (International Maize and Wheat Improvement Center 2015). Although global wheat production has reached $>700$ million tons at an annual increase rate of $1.6 \%$ (Food and Agriculture Organization of the United Nations 2019), it is insufficient to meet the accelerating global demand (Singh et al. 2016).

One main constraint to improving global wheat production is diseases, including leaf, stripe, and stem rusts (Aktar-Uz-Zaman et al. 2017; Singh et al. 2016). Leaf rust, incited by fungal pathogen Puccinia triticina, is more common than either stripe or stem rust. Yield losses caused by leaf rust occur in almost all wheat production

†Corresponding author: M. Pumphrey; m.pumphrey@wsu.edu

Funding: This study is part of the Triticeae Coordinated Agriculture Project (https://www.triticeaecap.org/) funded by the U.S. Department of Agriculture National Institute of Food and Agriculture.

*The $e$-Xtra logo stands for "electronic extra" and indicates that two supplementary data files and two supplementary tables are published online.

The author(s) declare no conflict of interest.

(C) 2019 The American Phytopathological Society areas of the world, varying from trace amounts to $>50 \%$ of the production. Severe leaf rust epidemics in the United States incurred yield loss of greater than 3 million tons between 2000 and 2004, with a total economic loss estimated at $>$ US\$350 million (HuertaEspino et al. 2011). Stripe rust, caused by Puccinia striiformis $\mathrm{f}$. $\mathrm{sp}$. tritici, is more frequently detected in the temperate regions of cooler and wetter environments (Liu et al. 2017b). Compared with leaf rust, stripe rust is adapted to a relatively narrower range of environmental conditions, but the damage attributable to stripe rust tends to be more severe. According to Beddow et al. (2015), an average of 5.47 million tons of global wheat, equivalent to US\$979 million, are lost annually as a result of stripe rust. Since 2000, with the emergence of new aggressive races, stripe rust has spread into the wheat-growing regions of warmer and dryer environments (Chen et al. 2010), which enhances the chances of multiple rusts simultaneously infecting wheat crops. Consequently, deployment of resistance to multiple diseases is desirable to mitigate losses of wheat production caused by both leaf rust and stripe rust.

Pyramiding of two or more resistance genes against rusts in individual cultivars is a common strategic goal for modern wheat breeding programs worldwide. Combinations of a couple of allstage resistance (ASR) and adult-plant resistance (APR) genes can offer near immunity and long-lasting resistance (Ellis et al. 2014; Singh et al. 2001; Tiwari et al. 2014). However, the genepyramiding process is time-consuming, and all genes in the pyramid should only be deployed together for maximum efficacy and longevity. Another type of desirable resistance that has been 
exploited in wheat breeding programs is the pleiotropic or tightly linked resistance loci against more than one disease. $\operatorname{Yr} 18 / \operatorname{Lr} 34$, Yr29/Lr46, and Yr46/Lr67 are pleiotropic effect genes conferring nonrace-specific APR to both stripe and leaf rusts during the late growth stages (Herrera-Foessel et al. 2014; Krattinger et al. 2009; William et al. 2003). Instead of providing complete immunity to certain rust races, these pleiotropic genes retard the infection process or reduce symptom development across all races of the pathogens. Cloning of $\mathrm{Yr} 18 / \mathrm{Lr} 34$ uncovered a transporter-mediated mechanism, which allowed a better understanding of its nonracespecific nature (Krattinger et al. 2009). Independent but tightly linked ASR genes also confer resistance to leaf and stripe rusts. The majority of these multigenic resistance sources were derived from translocations or introgressed segments of wheat relatives. Examples are $Y r 9-L r 26$, Yr17-Lr37 (Helguera et al. 2003), Yr30Lr27 (Mago et al. 2011; Singh et al. 2000), Yr35-Lr53 (Dadkhodaie et al. 2011), Yr37-Lr54 (Marais et al. 2005), Yr38-Lr56 (Marais et al. 2006), Yr40-Lr57 (Kuraparthy et al. 2007), Yr42-Lr62 (Marais et al. 2009), Yr47-Lr52 (Qureshi et al. 2017), and Yr70-Lr76 (Bansal et al. 2016). Closely linked molecular markers have been identified for these translocated segments, enabling expedient multipathogen resistance breeding with effectively diagnostic DNA markers.

With the objective of identifying pleiotropic or tightly linked resistance genes to both leaf and stripe rusts, a genome-wide association study (GWAS) for stripe rust resistance was performed on a spring wheat population that has already been characterized for leaf rust resistance (Gao et al. 2016).

\section{MATERIALS AND METHODS}

Plant materials. A collection of 294 spring wheat breeding accessions provided by the U.S. Department of Agriculture Agricultural Research Service Cereal Disease Laboratory was used in this study (Supplementary Data File S1). This collection was sampled from a larger GWAS panel of 381 genotypes (Gao et al. 2016) based on the seed accessibility. Fifty-eight accessions were leaf rust resistance gene near-isogenic lines (NILs) in the Thatcher background. The other accessions were cultivars or advanced breeding lines derived from the public or private wheat breeding programs mainly in North and South America.

Stripe rust phenotyping. Race-specific resistance to stripe rust at the seedling stage was conducted under the controlled conditions in a greenhouse. The 294 accessions were tested with P. striiformis f. sp. tritici races PSTv-4, PSTv-14, PSTv-18, PSTv37, and PSTv-40. For each race test, Avocet S (AvS) was used as a susceptible check, and $18 \mathrm{Yr}$ single-gene lines that are used to differentiate $P$. striiformis f. sp. tritici races (Wan and Chen 2014) were included to confirm the race identity. Three seeds of each accession were planted in one well of 96-well trays, and each race test was repeated once. The inoculated seedlings were kept in a dew chamber at $10^{\circ} \mathrm{C}$ and $100 \%$ humidity without light for $24 \mathrm{~h}$, and then they were moved to a rust-free growth chamber with condition settings of a diurnal temperature cycle gradually changing from $4^{\circ} \mathrm{C}$ at 2:00 AM to $20^{\circ} \mathrm{C}$ at 2:00 PM with a 16 -h photoperiod. The stripe rust reaction of individual accessions was recorded using the infection type (IT), on a scale of 0 to 9 (Line and Qayoum 1992), when AvS had full sporulation, about 18 to 20 days after inoculation.

Stripe rust phenotyping of the 294 accessions was conducted in fields near Pullman, Central Ferry, and Mount Vernon, Washington, in 2014 to 2016, following methods as previously described (Liu et al. 2017a, b, c). Seeds of each accession (5 g) were sown into 0.5$\mathrm{m}$ length at $0.3-\mathrm{m}$ spacing in the early spring. AvS was planted every 20 rows. Either AvS (for the Mount Vernon location) or another susceptible spring wheat Lemhi (for the Spillman and Central Ferry locations) was planted surrounding the field as the inoculum spreaders to ensure adequate and uniform infection. The collection was evaluated in five environments: the Spillman Agronomy Farm $\left(46^{\circ} 43^{\prime} 47.1972^{\prime \prime} \mathrm{N} 117^{\circ} 10^{\prime} 54.2568^{\prime \prime} \mathrm{W}\right)$ near Pullman, Washington in 2014 (SPM14), 2015 (SPM15), and 2016 (SPM16); the Central Ferry Farm (46 $38^{\prime} 9.816^{\prime \prime}$ N117 $47^{\prime} 24.0792^{\prime \prime} \mathrm{W}$ ) about 60 miles southwest of Pullman in 2015 (CLF15); and the Mount Vernon Northwest Washington Research and Extension Center ( $48^{\circ}$ $25^{\prime} 16.3776^{\prime \prime} \mathrm{N} 122^{\circ} 20^{\prime} 2.5692^{\prime \prime} \mathrm{W}$ ) about 340 miles northwest of Pullman in 2015 (MTV15). All field trials used a nonreplicated completely random design. Plants in the trials were naturally infected by $P$. striiformis f. sp. tritici (Liu et al. 2017a). Stripe rust reactions were recorded as IT and disease severity (SEV), estimated as the percentage (0 to $100 \%$ ) of the infected area of flag leaves (Peterson et al. 1948) from the boot to soft dough stages (GS 45 to 85) (Zadoks et al. 1974) depending on location. Heading date and plant height of each accession were scored in SPM15 and SPM16.

Statistical analyses of phenotypic data. Pairwise Pearson correlation coefficients among five environments were computed using the $\mathrm{R}$ function cor.test. Broad-sense heritability $\left(H^{2}\right)$ was calculated with the following formula:

$$
H^{2}=\sigma_{G}^{2} / \sigma_{P}^{2}
$$

where $\sigma_{\mathrm{G}}{ }^{2}$ is the genotypic variance and $\sigma_{\mathrm{P}}{ }^{2}$ is the phenotypic variance. The formula for phenotypic variance is as follows:

$$
\sigma_{P}^{2}=\left[\sigma_{G}^{2}+\left(\sigma_{E \times G}{ }^{2}+\sigma_{e}^{2}\right) / n\right]
$$

where $\sigma_{\mathrm{E}} \times \mathrm{G}^{2}$ is the variance of environment by genotype interaction, $\sigma_{\mathrm{e}}{ }^{2}$ is the residual variance, and $n$ is the environment number (Piepho and Möhring 2007). These variance components were dissected by analysis of variance generated from the PROC MIXED COVTEST procedure in SAS version 9.3 (SAS Institute Inc., Cary, NC). Genotype, environment, and genotype-byenvironment interaction were random variables in the analysis of variance (ANOVA) random-effects model. The PROC MIXED procedure was also used for estimating the best linear unbiased estimator (BLUE) of IT and SEV across five environments, with genotypes as the fixed effect and the other variables as random effects (Wolfinger et al. 1997).

Genotypic profile. The entire panel was genotyped using the Illumina iSelect 90K single nucleotide polymorphism (SNP) array that was previously described in Gao et al. (2016). The SNP marker profile was downloaded from the Triticeae Toolbox (T3) database (https://triticeaetoolbox.org/wheat/). Heterozygous alleles were converted to missing data. The SNPs with a missing marker frequency $>0.1$ and a minor allele frequency $<0.1$ were removed. After filtering, a total of 15,594 high-quality polymorphic SNPs were retained for further analyses. Additionally, diagnostic markers for pleiotropic resistance genes $\mathrm{Yr} 18 / \mathrm{Lr} 34$ and $\mathrm{Yr} 46 / \mathrm{Lr} 67$ and tightly linked genes $\mathrm{Yr} 17-\mathrm{Lr} 37$ and $\mathrm{Yr} 30-\mathrm{Sr} 2-\mathrm{Lr} 27$ were used to genotype the entire collection, and the marker data were included for association analysis. Information on these diagnostic markers is provided in Supplementary Table S1.

Population structure and kinship. The population structure of the spring wheat panel was dissected by both Bayesian modelbased clustering and principal component analysis (PCA). Bayesian model-based clustering was estimated using STRUCTURE version 2.3.4 (Falush et al. 2003; Pritchard et al. 2000) and followed parameter settings as previously described (Liu et al. 2017a, b, c). PCA was estimated using JMP Genomics version 6.0. The number of subpopulations that best represented this collection was determined by the ad hoc statistic $\Delta k$ plot of Bayesian model-based clustering (Evanno et al. 2005) combined with the scree plot of PCA. To further explore the genetic relatedness of pairwise accessions in the collection, a kinship matrix $(K)$ was generated in JMP Genomics version 6.0 using the identical-by-state (IBS) algorithm. 
Association analysis. The R package Genome Association and Prediction Integrated Tool (GAPIT) (Lipka et al. 2012) was used to conduct the marker-trait association (MTA) analysis. A couple of models were performed on this collection, including the general linear model (GLM) (Riethmüller et al. 2002), the GLM with the membership coefficients of three subpopulations generated by Bayesian model-based clustering $(Q)$, the mixed linear model (MLM) with $K$ as a random variable, and the MLM with $Q$ and $K$ as variables. The optimal model that best fits the seedling and adultstage phenotypes was MLM with $K$ (hereafter, $\mathrm{MLM}+K$ ) according to the Bayesian information criterion values (Supplementary Table S2). Pearson correlation coefficients were calculated between field resistance (BLUE_IT, BLUE_SEV), heading date, and plant height. Plant height was significantly $(P<0.05)$ correlated with both BLUE_IT and BLUE_SEV, but heading date was not. In this case, plant height was added into the $\mathrm{MLM}+K$ model as a covariate when analyzing adult-plant phenotype data. GWAS tests were performed separately for IT and SEV in each environment as well as the BLUEs generated from data across five environments. We used the marker-wise $P$ value of 0.001 as the threshold to declare significant MTAs and the false discovery rate-corrected $P$ value of 0.1 to select the highly significant MTAs. The physical positions of significant SNPs were obtained from the International Wheat Genome Sequencing Consortium (IWGSC) website (IWGSC RefSeq version 1.0, http://www. wheatgenome.org), and the genetic positions of significant SNPs were obtained from the 90K SNP consensus map (Wang et al. 2014).

The QTL interval boundaries were determined using the pairwise linkage disequilibrium (LD) correlation coefficients of significant markers with $r^{2} \geq 0.5$ coupled with the genetic distances $\leq 10 \mathrm{cM}$. The pairwise LD $r^{2}$ was calculated using Haploview version 4.2 (Barrett et al. 2005). We chose the tagging marker for each QTL with the criteria of the smallest marker-wise $P$ value, the largest phenotypic variation (PVE), and the largest number of races/ environments in which significant associations were detected (Gao et al. 2016; Liu et al. 2017d; Naruoka et al. 2015). The PVE for each QTL was determined by the PVE of the tagging SNP.

To identify the pleiotropic/tightly linked QTL for stripe and leaf rust resistance, we compared the physical positions of stripe rust resistance QTL identified in the current study to the leaf rust resistance QTL identified in the same panel (Gao et al. 2016) based on IWGSC RefSeq version 1.0 (Appels et al. 2018). The R package RIdeogram (Hao et al. 2018) was used to visualize and map the identified stripe rust and leaf rust resistance QTL onto wheat chromosomes. The length of each chromosome and its centromere position were obtained from IWGSC RefSeq version 1.0 (Appels et al. 2018).

An integrated genetic map consisting of 235 previously documented $Y r$ genes/QTL as well as different genetic marker

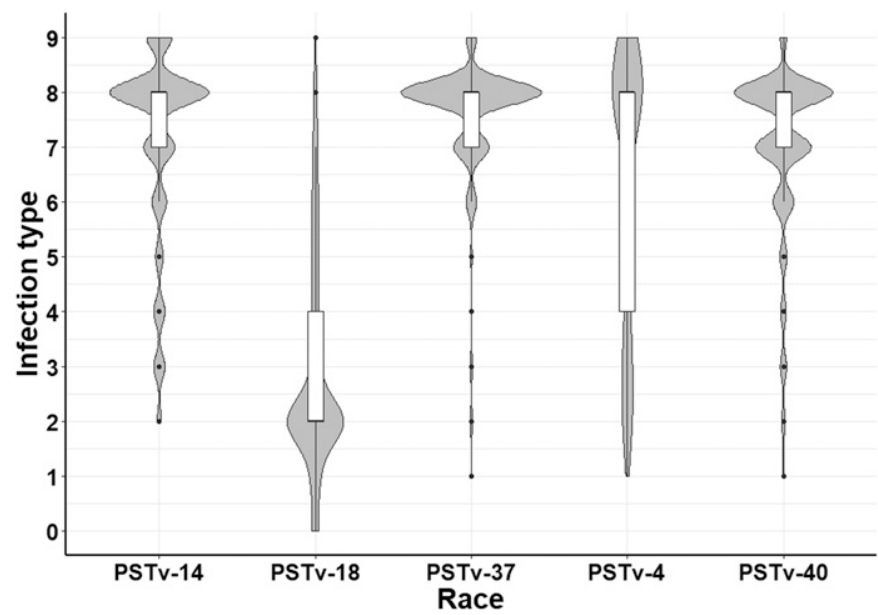

Fig. 1. The distributions of infection type at the seedling stage against five races of Puccinia striiformis f. sp. tritici. types, including SNPs, simple sequence repeats, diversity array technology, and expressed sequence tag markers, generated by Maccaferri et al. (2015), was used to compare the colocalizations between the QTL identified in the current study and the previously reported $Y r$ genes or QTL.

\section{RESULTS}

Phenotypic variation in stripe rust resistance. In the tests with individual $P$. striiformis $\mathrm{f}$. sp. tritici races at the seedling stage, PSTv-37 was more virulent to the current panel than any of the other four races, with 92,6 , and $2 \%$ of accessions showing susceptibility (IT from 7 to 9), moderate susceptibility (IT from 4 to 6), and resistance (IT from 0 to 3), respectively. To avoid false-positive error, the phenotype to PSTv-37 was not used for GWAS analysis because there were not enough resistant accessions in the population (Fig. 1). The IT distributions against $P$. striiformis $\mathrm{f}$. sp. tritici races PSTv-4, PSTv-14, and PSTv-40 were skewed to susceptibility, with susceptible accession frequencies of 65,76 , and $79 \%$, respectively. However, the IT distribution against PSTv18, the least virulent race identified thus far in North America, was skewed to resistance with a resistant accession frequency of $74 \%$.

At the adult-plant stage in the field tests, IT and SEV distributions were nearly normal or skewed toward low IT and SEV in most of the environments, except MTV15, where the population had a skewed distribution toward high IT and SEV, with the mean IT and SEV equal to 6.0 and $60.3 \%$, respectively; in contrast, the mean IT and SEV within the other four environments ranged from 3.7 to 5.1 and 14.8 to $32.0 \%$, respectively (Fig. 2). Pearson correlation coefficients across five environments ranged from 0.49 to 0.74 for IT and from 0.36 to 0.66 for SEV. Environment MTV15 displayed lower correlations with the other environments for both IT and SEV, with a range from 0.49 to 0.74 for IT and from 0.36 to 0.66 for SEV. As expected, correlations between IT and SEV within the same environment were greatest, ranging from 0.61 to 0.91 (Fig. 3). Across the five environments, the broad-sense heritability was 0.89 for IT and 0.77 for SEV.

Population structure and relationship with stripe rust resistance phenotype. Both model-based and PCA-based structure analyses found three major subpopulations in this collection, which is the same as population structure analysis in Gao et al. (2016). Accessions in subpopulation 1 were Thatcher NILs or had Thatcher in their pedigree. The first subpopulation, hence, was called the "Thatcher group," hereafter. The other two subpopulations consisted of cultivars or breeding lines mainly collected throughout North and South America. Further details of the population structure are described in Gao et al. (2016).

The Thatcher group was more susceptible to stripe rust than the other two groups in all field environments. The BLUE_IT and SEV values for the Thatcher group were significantly larger $(P<0.05)$ than the others (Table 1). The BLUE_IT and BLUE_SEV values for the second group were slightly smaller than those for the third group, but no significant difference was observed between these two groups. In the single-race seedling tests, the Thatcher group was significantly more resistant against PSTV-4 than the other two groups, whereas the second subgroup was significantly more resistant against PSTv-14 and PSTv-37 than the others. For PSTv-18, all three subgroups showed substantial resistance, but the Thatcher and the second subgroups were significantly more resistant than the third subgroup. There was no significant difference between the three subgroups for PSTV-40 responses (Table 1).

Dissection of genetic architecture of stripe rust resistance. The previous GWAS study for leaf rust resistance revealed pleiotropic rust resistance gene $\operatorname{Yr} 18 / \mathrm{Lr} 34$ on chromosome 7D associated with both ASR and APR to leaf rust in the collection (Gao et al. 2016). As an internal control, the diagnostic marker data for Yr18/Lr34 were incorporated into the current GWAS for stripe rust 
resistance. Unsurprisingly, at a resistance allele frequency of $35 \%$, Yr18/Lr34 showed the most significant associations with IT and SEV in all environments except SPM14 at the adult-plant stage compared with the other MTAs, and it accounted for 3.7 to $12.3 \%$ of the PVE (Table 2). This result validates the effectiveness of the MLM+K model for stripe rust resistance data of this collection. $\operatorname{Yr} 17-\operatorname{Lr} 37$ and Yr46/Lr67 were also detected in the population, with resistance allele frequencies of $2.0,1.0$, and $6.8 \%$, respectively. Because of the low allele frequency, markers of $\mathrm{Yr} 17-\mathrm{Lr} 37, \mathrm{Yr} 46 / \mathrm{Lr67}$, and $\mathrm{Yr} 30-\mathrm{Sr} 2-$ Lr27 were excluded when conducting the GWAS.

An additional 21 QTL that showed significant or highly significant associations with stripe rust resistance were detected on chromosomes 1B, 1D, 2B, 3B, 4A, 5A, 5B, 5D, 6A, 6B, 7A, and 7B (Table 2; Supplementary Data File S2). Among these QTL, 17 were associated with IT against the tested $P$. striiformis $\mathrm{f}$. sp. tritici races at the seedling stage, and therefore were most likely conferring ASR. The PVE explained by the 17 QTL ranged from 2.1 to $14.1 \%$. Four ASR QTL (Yrswp-2B.1, Yrswp-2B.2, Yrswp2B.3, and Yrswp-2B.4) were present in tandem at a large interval of $\sim 140 \mathrm{Mb}$ on the long arm of chromosome $2 \mathrm{~B}$. These four QTL had highly significant associations with resistance to PSTV-4, and Yrswp-2B.2 was also significantly associated with PSTv-18. On chromosome 3BS, Yrswp-3B, tagged by SNP IWB35950, was associated with not only resistance to PSTV-40 at the seedling stage but also to resistance as measured by IT in environment SPM16 and BLUE values across all environments at the adult-plant stage. Yrswp-3B accounted for 3.9\% of PVE for ASR and for 2.8 to $4.6 \%$ for field resistance. Four QTL (QYrswp-6B.1, QYrswp-6B.2, QYrswp-6B.3, and QYrswp-7A) were exclusively associated with field resistance in at least two environments at the adult-plant stage, which potentially represents APR QTL. The PVE explained by individual QTL ranged from 3.2 to $15.5 \%$, and the cumulative PVE values of these four QTL coupled with $\mathrm{Yr} 18 / \mathrm{Lr} 34$ were $43.9 \%$ for BLUE_IT and $34.4 \%$ for BLUE_SEV.

Pleiotropic or tightly linked QTL for stripe and leaf rust resistance. With the aim of assessing the possible pleiotropic or tightly linked QTL for both stripe and leaf rust resistance besides Yr18/Lr34, Yr17-Lr37, Yr46/Lr67, and Yr30-Lr27, the remaining stripe rust resistance QTL identified in the current study were compared with the leaf rust resistance QTL identified in the same panel (Gao et al. 2016). According to the wheat 90K SNP consensus map (Wang et al. 2014) and IWGSC RefSeq version 1.0 (Appels et al. 2018), three stripe rust resistance QTL (Yrswp-2B, Yrswp-3B, and $Y r s w p-7 B$ ) located at the same regions of leaf rust resistance QTL $2 B \_3,3 B \_t 2$, and 7B_4 (Gao et al. 2016), respectively (Fig. 4; Table 2). In a comparison of significant SNPs of stripe rust resistance QTL with leaf rust resistance QTL, only Yrswp-2B.1 shared common SNPs (IWB72407 and IWB64322) with 2B_3. $I W B 72407$ and $I W B 64322$ were in complete $\operatorname{LD}\left(r^{2}=1.0\right)$ with each other. Nevertheless, haplotype "CG" for Yrswp-2B.1/2B_3 was the resistance-associated haplotype for stripe rust, whereas it was the susceptibility-associated haplotype for leaf rust. In other words, these two resistance genes were linked in repulsion.

Haplotype analysis was conducted to further determine the relationships between Yrswp-3B and $3 B \_t 2$ and $Y r s w p-7 B$ and $7 B \_$ 4. Yrswp-7B was not linked with $7 B \_4$ because IWB60899 for Yrswp-7B and $I W B 64015$ for $7 B \_4$ had a LD $r^{2}$ equal to 0.005 . However, Yrswp-3B was tightly linked with $3 B \_t 2$ because $I W B 35950$ and $I W B 72134$ for Yrswp-3B and IWB74350 for $3 B \_t 2$ were in high $\operatorname{LD}\left(r^{2}=0.64\right.$ to 0.78$)$. Furthermore, the most frequent haplotype, "ACT," of $3 B \_t 2$ and Yrswp-3B, which was present in $68 \%$ of the accessions, conferred resistance to both stripe and leaf rusts. This haplotype accounted for 2.8 to $4.6 \%$ of PVE for stripe rust resistance and $4 \%$ of PVE for leaf rust resistance. In summary, Yrswp$3 B / 3 B \_t 2$ is a potential QTL for resistance to both leaf and stripe rusts.

Distributions of favorable alleles of identified QTL among three subpopulations. The stripe rust resistanceassociated allele frequencies of identified QTL in the entire population and three subpopulations are summarized in Table 3. The resistance allele frequency for $\mathrm{Yr} 18 / \mathrm{Lr} 34$ was 0.35 in the entire population, and a higher frequency was found in subgroup $3(0.43)$ than the other two subgroups (0.14 and 0.39). The favorable allele frequency for $Y r s w p-3 B / 3 B \_t 2$ was 0.76 in the entire population. The Thatcher group $(0.88)$ had a higher favorable allele frequency than either subgroup 2 (0.71) or subgroup $3(0.73)$. In contrast, the resistance alleles for the three field resistance QTL on chromosome 6B (QYrswp-6B.1, QYrswp-6B.2, and QYrswp-6B.3) were nearly absent in the Thatcher group but had higher favorable allele frequencies in the other two groups, except that the resistance allele for $Q Y r s w p-6 B .3$ was also very low in subgroup 3. Nine ASR QTL (Yrswp-1D.1, Yrswp-2B.2, Yrswp-2B.3, Yrswp-2B.4, Yrswp-3B, Yrswp-4A, Yrswp-5A, Yrswp-5B.2, and Yrswp-6A) had the highest resistance allele frequencies in the Thatcher group, whereas seven QTL (Yrswp-1B, Yrswp-1D.2, Yrswp-5B.1, Yrswp-5D.1, Yrswp5D.2, Yrswp-7A, and Yrswp-7B) were almost absent.

\section{DISCUSSION}

In this study using GWAS, we identified stripe rust resistance loci in a spring wheat collection whose genetic architecture of leaf rust resistance has already been assessed (Gao et al. 2016). A total of 333 SNP markers within 46 unique QTL on 18 chromosomes were reported by Gao et al. (2016) to have significant associations with leaf rust resistance. In our stripe rust resistance study, 21 QTL (165 SNPs) on 12 chromosomes as well as $\operatorname{Yrl} 18 / \operatorname{Lr} 34$ were detected.
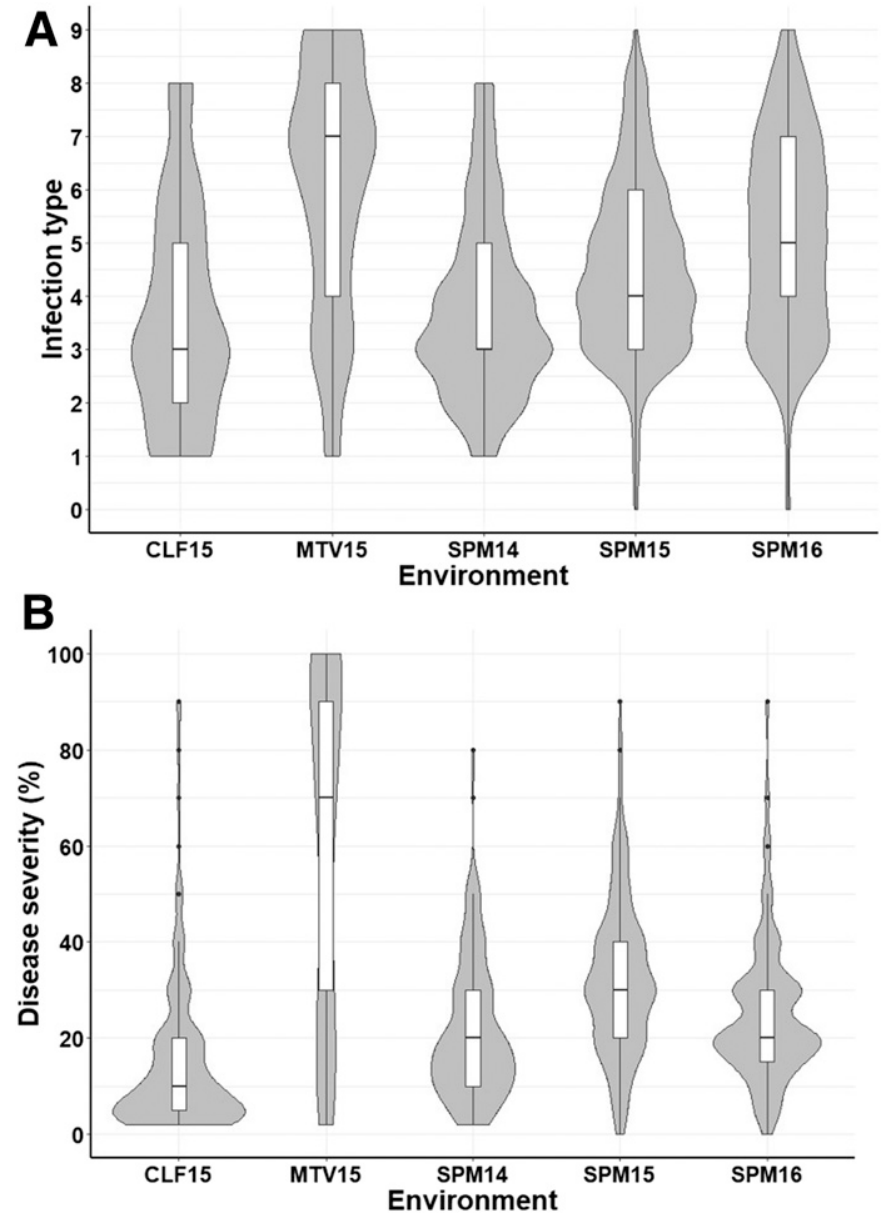

Fig. 2. The distributions of stripe rust resistance at the adult-plant stage: A, infection type, and $\mathbf{B}$, disease severity. Each environment was referred to as SPM14, SPM15, and SPM16 for trials at Spillman Agronomy Farm in 2014, 2015, and 2016, respectively; CLF15 for the trial at Central Ferry in 2015; and MTV15 for the trial at Mt. Vernon in 2015. 
Among them, three stripe rust resistance QTL on chromosomes 2B, 3B, and 7B colocated with leaf rust resistance QTL, but only Yrswp$3 B$ and $3 B \_t 2$ were potential multiple resistance QTL in this population.
On the long arm of chromosome 2B, IWB72407 and IWB64322 are commonly present in the stripe rust resistance QTL Yrswp-2B.1 and the leaf rust resistance QTL 2B_3. However, Yrswp-2B.1/2B_3 is unable to simultaneously improve resistance to both rusts because

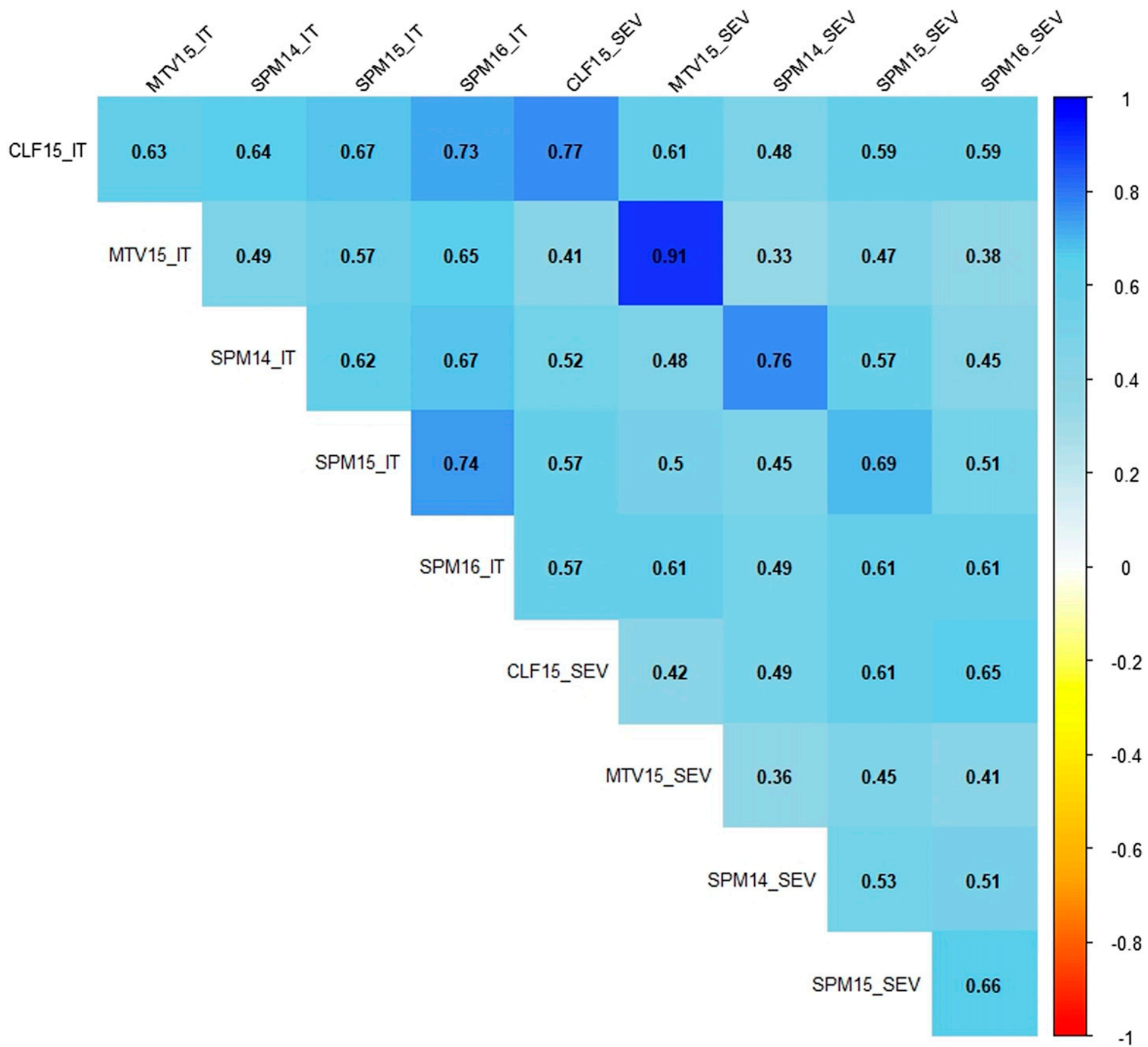

Fig. 3. Pearson's correlation coefficients of infection type (IT) and disease severity (SEV) among five field environments. Each environment is referred to as SPM14, SPM15, and SPM16 for trials at Spillman Agronomy Farm in 2014, 2015, and 2016, respectively; CLF15 for the trial at Central Ferry in 2015; and MTV15 for the trial at Mt. Vernon in 2015. All correlations were significant at $P<0.05$.

TABLE 1. Means of infection type (IT) and disease severity (SEV) against stripe rust at seedling and adult-plant stages in the entire population and three subpopulations $^{2}$

\begin{tabular}{|c|c|c|c|c|c|}
\hline Plant stage & Trait/race & Entire population & $\begin{array}{l}\text { Subpopulation } 1 \\
\quad(n=65)\end{array}$ & $\begin{array}{l}\text { Subpopulation } 2 \\
\quad(n=132)\end{array}$ & $\begin{array}{c}\text { Subpopulation } 3 \\
(n=97)\end{array}$ \\
\hline \multirow[t]{2}{*}{ Adult-plant stage } & BLUE_IT & 4.6 & $5.6^{\mathrm{a}}$ & $4.3^{\mathrm{b}}$ & $4.5^{\mathrm{b}}$ \\
\hline & BLUE SEV & 30.6 & $35.3^{\mathrm{a}}$ & $28.6^{\mathrm{b}}$ & $30.2^{\mathrm{b}}$ \\
\hline & IT (PSTv-14) & 7.1 & $7.6^{\mathrm{a}}$ & $6.6^{\mathrm{b}}$ & $7.5^{\mathrm{a}}$ \\
\hline & IT (PSTv-18) & 2.8 & $2.1^{\mathrm{a}}$ & $2.6^{\mathrm{a}}$ & $3.6^{\mathrm{b}}$ \\
\hline & IT (PSTv-37) & 7.6 & $8.0^{\mathrm{a}}$ & $7.4^{\mathrm{b}}$ & $7.7^{\mathrm{a}}$ \\
\hline & IT (PSTV-40) & 7.1 & 7.1 & 7.0 & 7.1 \\
\hline
\end{tabular}

${ }^{\mathrm{z}}$ Different superscript letters for the subpopulation means showed a significant difference $(P<0.05)$ using one-way analysis of variance. BLUE $=$ best linear unbiased estimator. 
resistance-associated alleles for IWB72407 and IWB64322 are actually susceptible alleles for leaf rust (Gao et al. 2016). Therefore, this QTL should be avoided by wheat breeding programs whose target areas have occurrence of stripe and leaf rusts, but the negative association is worthy of further study.

The most promising multiple resistance QTL identified in this study, Yrswp-3B/3B_t2, was located in the telomere region of chromosome 3BS. Yrswp-3B was associated with resistance to P. striiformis f. sp. tritici race PSTV-40 as well as IT in environment SPM16 and BLUE. The leaf rust resistance QTL $3 B \_t 2$ was associated with response to a mixture of $P$. triticina races and multiple field environments (Gao et al. 2016). These associations suggest that the QTL complex Yrswp-3B/3B_t2 appears to be effective against more $P$. triticina races than $P$. striiformis $\mathrm{f}$. $\mathrm{sp}$. tritici races. Previously documented tightly linked gene $\mathrm{Yr} 30-\mathrm{Sr} 2-$ Lr27 was also reported in chromosome 3BS close to the telomere region. However, the average LD $r^{2}$ between $Y r s w p-3 B / 3 B \_t 2$ and $\mathrm{Yr} 30-\mathrm{Sr} 2-\mathrm{Lr} 27$ in our population was 0.025. By exploring the resistance allele distributions, we found that the resistance haplotypes for $Y r s w p-3 B / 3 B \_t 2$ were widely present in all three subpopulations, with a resistance allele frequency of 88,71 , and $73 \%$, respectively. However, the resistance allele for $\mathrm{Yr} 30-\mathrm{Sr} 2-\mathrm{Lr} 27$ was exclusively present in subpopulation 2 , with an allele frequency of $15 \%$. These findings suggest that $\mathrm{Yrswp}-3 \mathrm{~B} / 3 \mathrm{~B}_{-} t 2$ and $\mathrm{Yr} 3 \mathrm{O}-\mathrm{Sr} 2-$ $L r 27$ were not linked with each other. However, biparental mapping was needed to further confirm whether Yrswp-3B/3B_t2 and Yr3O$S r 2-L r 27$ were the same pleiotropic gene. In a comparison of the genetic positions with documented rust resistance genes, Yrswp-3B/ $3 B \_t 2$ did not overlap with any other previously published stripe rust and leaf rust resistance genes. Therefore, Yrswp-3B/3B_t2 is probably a novel QTL. Because the resistance haplotype for Yrswp$3 B / 3 B \_t 2$ was widely present in the current panel, this chromosomal segment is most likely under selection pressure throughout North and South American wheat breeding programs.

Besides Yrswp-3B/3B_t2 we also detected the previously documented pleiotropic rust genes $Y r 18 / L r 34$ and $Y r 46 / L r 67$ and tightly linked genes $\operatorname{Yr} 17-\operatorname{Lr} 37$ and $\operatorname{Yr} 30-S r 2-L r 27$ in this population. Thatcher NILs RL6058, RL6081, and RL6077 in

TABLE 2. Significant quantitative trait loci (QTL) that associated with resistance to Puccinia striiformis f. sp. tritici

\begin{tabular}{|c|c|c|c|c|c|c|c|c|c|c|c|}
\hline QTL & Type $^{r}$ & Chromosome & $\begin{array}{l}90 \mathrm{~K} \text { cons } 2014 \\
\text { position }(\mathrm{cM})^{\mathrm{s}}\end{array}$ & $\begin{array}{l}\text { RefSeq version } 1.0 \\
\text { position }(b p)^{t}\end{array}$ & Tag-SNP ${ }^{u}$ & Allele $^{v}$ & $\operatorname{PVE}(\%)^{\mathrm{w}}$ & MTA $^{x}$ & $L r^{y}$ & $Y r^{\mathrm{z}}$ & References \\
\hline Yrswp-1B & ASR & 1B & $107.4-109.7$ & $632753937-636738140$ & IWB47288 & $T / G$ & 4.5 & PSTv-40 & - & YrExpl & $\begin{array}{l}\text { Lin and Chen } \\
\text { (2007) }\end{array}$ \\
\hline Yrswp-1D.I & ASR & 1D & 67.7 & 250140206 & IWB6869 & $T / G$ & 2.8 & PSTv-14 & - & - & - \\
\hline Yrswp-1D.2 & ASR & 1D & 115.6 & $435151463-435933420$ & IWB9896 & $\mathbf{A} / \mathrm{G}$ & 3.6 & PSTv-14 & - & - & - \\
\hline Yrswp-2B.I & ASR & $2 \mathrm{~B}$ & $107.01-108.4$ & $612686386-637574450$ & IWB72408 & $\mathbf{A} / \mathrm{G}$ & $2.1-6.2$ & PSTv-4 & $2 B \_3$ & - & - \\
\hline Yrswp-2B.2 & ASR & $2 \mathrm{~B}$ & $109.14-126.53$ & $657844062-670837337$ & IWB12654 & $\mathrm{T} / \mathbf{C}$ & $2.2-5.3$ & PSTv-4, PSTv-18 & - & $\begin{array}{l}Y r 5, Y r 7, Y r 44 \\
\quad Y r 53, Y r S P\end{array}$ & $\begin{array}{l}\text { Feng et al. (2015), } \\
\text { McGrann et al. } \\
\text { (2014), Xu et al. } \\
\text { (2013) }\end{array}$ \\
\hline Yrswp-2B.3 & ASR & $2 \mathrm{~B}$ & $113.36-116.83$ & $694051080-703976259$ & IWB19972 & $\mathrm{A} / \mathrm{G}$ & $2.1-4.3$ & PSTv-4 & - & $\begin{array}{l}Y r 5, Y r 7, Y r 44 \\
\quad Y r 53, Y r S P\end{array}$ & $\begin{array}{l}\text { Feng et al. (2015), } \\
\text { McGrann et al. } \\
\text { (2014), Xu et al. } \\
\text { (2013) }\end{array}$ \\
\hline Yrswp-2B.4 & ASR & 2B & $114.82-130.62$ & $709423590-752485089$ & IWB34664 & $\mathrm{T} / \mathrm{C}$ & $2.1-4.2$ & PSTv-4 & - & $\begin{array}{l}Y r 5, Y r 7, Y r 44 \\
\quad Y r 53, Y r S P\end{array}$ & $\begin{array}{l}\text { Feng et al. (2015), } \\
\text { McGrann et al. } \\
\text { (2014), Xu et al. } \\
\text { (2013) }\end{array}$ \\
\hline Yrswp-3B & ASR & 3B & 51.1 & $3240217-3228129$ & IWB35950 & $\mathrm{T} / \mathrm{C}$ & $2.8-4.6$ & $\begin{array}{l}\text { PSTv-40, SPM16_IT, } \\
\text { BLUE_IT }\end{array}$ & $3 B \_t 2$ & - & - \\
\hline Yrswp-4A & ASR & $4 \mathrm{~A}$ & 108.7 & $663281171-663282832$ & IWB55277 & $\mathbf{A} / \mathrm{G}$ & 2.3 & PSTv-4 & - & - & - \\
\hline Yrswp-5A & ASR & $5 \mathrm{~A}$ & $92.9-93.2$ & 594143506-594576820 & IWB26265 & $\mathrm{T} / \mathbf{C}$ & 3.9 & PSTv-40 & - & - & - \\
\hline Yrswp-5B.1 & ASR & $5 \mathrm{~B}$ & $68.6-78.0$ & $520886418-539293256$ & IWA5478 & $\mathbf{A} / \mathrm{G}$ & 14.1 & PSTv-14 & - & $\begin{array}{l}\text { Qyrco.wpg-5B_coda, } \\
\text { QYr-5B_Oligoculm }\end{array}$ & $\begin{array}{l}\text { Case et al. (2014), } \\
\text { Suenaga et al. } \\
(2003)\end{array}$ \\
\hline Yrswp-5B.2 & ASR & 5B & 90.3 & 546827149-546849099 & IWB3660 & $\mathrm{T} / \mathbf{C}$ & 2.9 & PSTv-14 & - & - & - \\
\hline Yrswp-5D.I & ASR & $5 \mathrm{D}$ & 67.5 & $132880061-154539793$ & IWB52508 & $\mathrm{T} / \mathrm{C}$ & 2.8 & PSTv-4 & - & $\begin{array}{l}\text { Yrcaas-5DS } \\
\quad \text { jingshuang } 16\end{array}$ & Ren et al. (2015) \\
\hline Yrswp-5D.2 & ASR & $5 \mathrm{D}$ & 67.5 & 221012593 & IWB34503 & $\mathrm{T} / \mathbf{G}$ & 2.1 & PSTv-4 & - & $\begin{array}{l}\text { Yrcaas-5DS_- } \\
\quad \text { jingshuang } 16\end{array}$ & Ren et al. (2015) \\
\hline Yrswp-6A & ASR & $6 \mathrm{~A}$ & 15.7 & 3852742 & IWA272 & $\mathrm{T} / \mathrm{C}$ & 3.5 & PSTv-4 & - & QYr.uga-6A_26R6I & Hao et al. (2011) \\
\hline QYrswp-6B.1 & APR & $6 \mathrm{~B}$ & 33.8 & 30147276 & IWA4010 & $\mathrm{T} / \mathrm{C}$ & $3.2-9.7$ & $\begin{array}{l}\text { CLF15_IT, SPM14_IT, } \\
\text { SPM15_IT, SPM16_IT, } \\
\text { BLUE_IT }\end{array}$ & - & $\begin{array}{l}\text { QYr.ufs-6B_Kariega, } \\
\text { QYr.TAM 111, } \\
\text { QYr.caas-6BS.2_Naxos }\end{array}$ & $\begin{array}{l}\text { Prins et al. (2011), } \\
\text { Ren et al. (2012) }\end{array}$ \\
\hline QYrswp-6B.2 & APR & $6 \mathrm{~B}$ & $48.5-57.1$ & 112885924-123747825 & IWB20486 & $\mathrm{T} / \mathrm{C}$ & $3.2-15.5$ & $\begin{array}{l}\text { CLF15_IT, CLF15_SEV, } \\
\text { MTV15_IT, SPM14_IT, } \\
\text { SPM15_IT, SPM16_IT, } \\
\text { BLUE_IT, BLUE_SEV, } \\
\text { SPM15_SEV }\end{array}$ & - & $\begin{array}{l}\text { QYr.wgp-6BS.2_Stephens, } \\
\text { QYr.sun-6B_Janz }\end{array}$ & $\begin{array}{l}\text { Bansal et al. } \\
\text { (2011), Santra } \\
\text { et al. (2008) }\end{array}$ \\
\hline QYrswp-6B.3 & APR & $6 \mathrm{~B}$ & 57.4 & 135112726 & IWB33273 & $\mathbf{A} / \mathrm{G}$ & $3.7-4.3$ & $\begin{array}{l}\text { MTV15_SEV, SPM15_SEV, } \\
\text { BLUE_SEV }\end{array}$ & - & - & - \\
\hline QYrswp-7A & APR & $7 \mathrm{~A}$ & 136.2 & 636889961 & IWA6004 & $\mathbf{A} / \mathbf{C}$ & $3.8-3.9$ & SPM15_IT, SPM16_IT & - & IWA4996, Yrxyl & $\begin{array}{l}\text { Zegeye et al. } \\
\text { (2014), Zhou } \\
\text { et al. (2011) }\end{array}$ \\
\hline Yrswp-7A & ASR & $7 \mathrm{~A}$ & $228.4-232.11$ & $731271409-732587216$ & IWB71711 & $\mathrm{T} / \mathrm{C}$ & 4.1 & PSTv-40 & - & IWA7592 & Bulli et al. (2016) \\
\hline Yrswp-7B & ASR & 7B & $159.0-171.1$ & $731269292-731987449$ & IWB60899 & $\mathrm{A} / \mathbf{G}$ & 3.9 & PSTv-40 & $7 B \_4$ & Yr59, Yr52 & $\begin{array}{l}\text { McIntosh et al. } \\
\text { (2014) }\end{array}$ \\
\hline Yr18/Lr34 & APR & $7 \mathrm{D}$ & 35 & $47411056-47425484$ & Yr18/Lr34 & T/A & $3.7-12.3$ & $\begin{array}{l}\text { CLF15_IT, CLF15_SEV, } \\
\text { MTV15_IT, MTV15_SEV, } \\
\text { SPM15_SEV, SPM16_IT, } \\
\text { SPM16_SEV, BLUE_IT, } \\
\text { BLUE_SEV }\end{array}$ & $\operatorname{Lr} 34$ & Yrl8/Lr34 & $\begin{array}{l}\text { Suenaga et al. } \\
\text { (2003) }\end{array}$ \\
\hline
\end{tabular}

${ }^{\mathrm{r}}$ QTL types include all-stage resistance (ASR) and adult-plant resistance (APR).

s Position of each single nucleotide polymorphism (SNP) based on the 90K wheat consensus map (Wang et al. 2014).

$\mathrm{t}$ Position of each SNP based on International Wheat Genome Sequencing Consortium IWGSC RefSeq version 1.0 (http://www.wheatgenome.org).

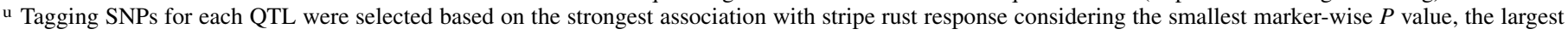
phenotypic variance (PVE) explained by the marker, and the largest number of races/environments in which significant associations were detected with the marker.

$\checkmark$ The resistance allele for each QTL is bolded.

${ }^{w}$ PVE explained by the tagging SNP for each QTL.

x Marker-trait associations (MTAs) highlighted in bold had significance levels of false discovery rate-adjusted $P<0.1$.

${ }^{y}$ Leaf rust resistance $(\mathrm{Lr})$ QTL identified in Gao et al. (2016) that colocated with stripe rust resistance QTL identified in this study.

z Stripe/yellow rust resistance $(Y r)$ QTL that were previously reported to overlap with QTL identified in this study. 
subpopulation 1 were identified to carry resistance alleles for Yr18/Lr34, Yr17-Lr37, and Yr46/Lr67, respectively. This finding confirmed the accuracy of our genotyping results because these lines are the NILs for these genes in the Thatcher background (Draz et al. 2015). In addition, four cultivars (INIA_MIRLO, INIA_
CARANCHO, INIA_CARPINTERO, and INIA_CHIMANGO) from the Uruguayan program at La Estanzuela and advanced breeding line MN05209 bred by the University of Minnesota in subpopulation 2 also contained $\mathrm{Yr}$ 17-Lr37; in addition, CHENAB70 from the International Maize and Wheat Improvement
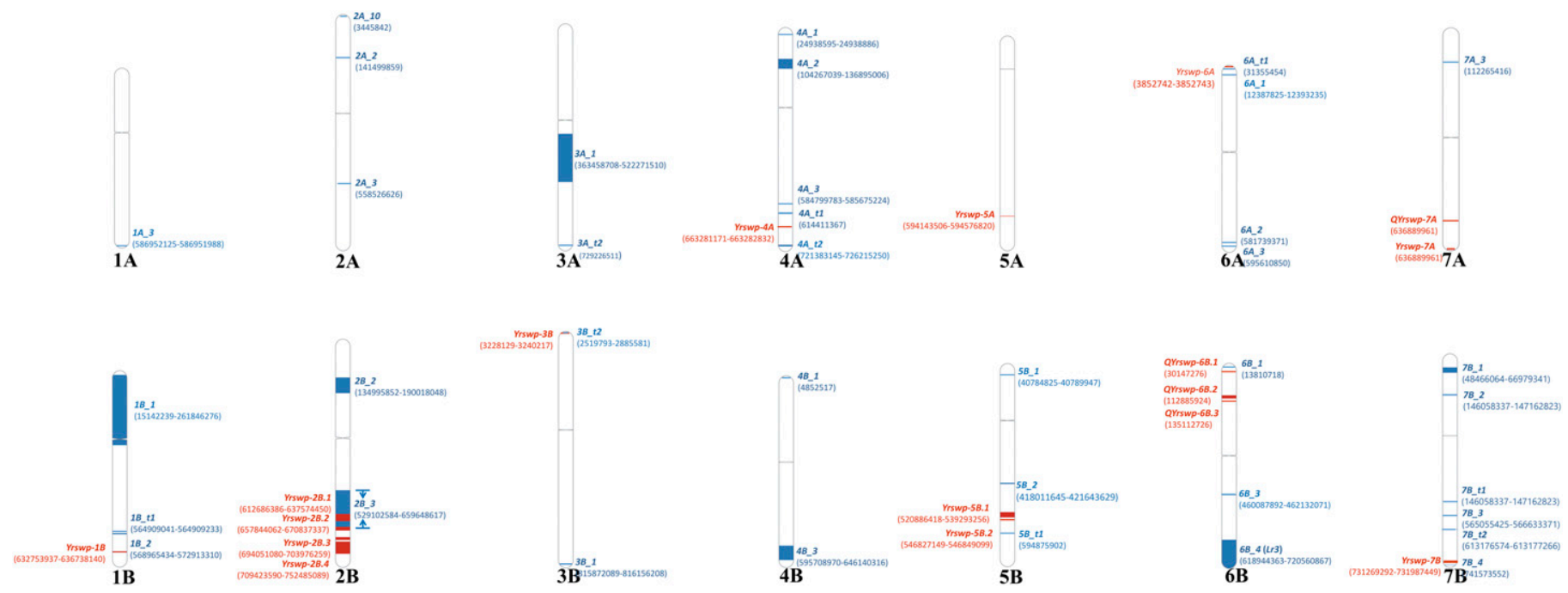

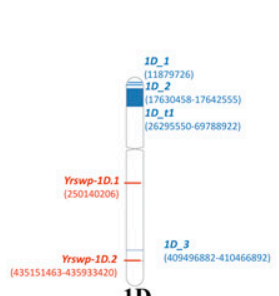

10

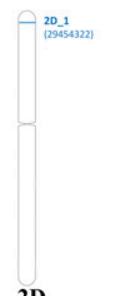

2D

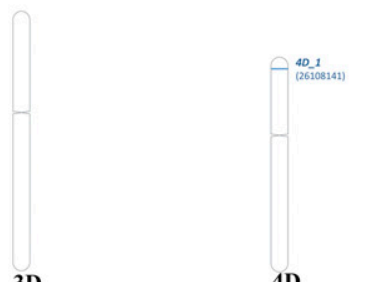

4D
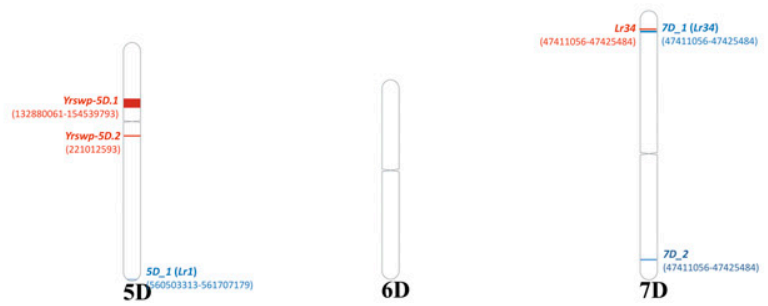

$7 \mathrm{D}$

Fig. 4. Chromosome positions of stripe rust and leaf rust resistance QTL. Stripe rust resistance QTL identified in the current study are presented on the left side of the chromosomes. Leaf rust resistance QTL identified previously are on the right side of the chromosomes. The numbers in the bracket were the start and end positions of QTL based on International Wheat Genome Sequencing Consortium IWGSC RefSeq version 1.0.

TABLE 3. The distribution of resistance allele frequencies for identified stripe rust resistance loci in three subpopulations

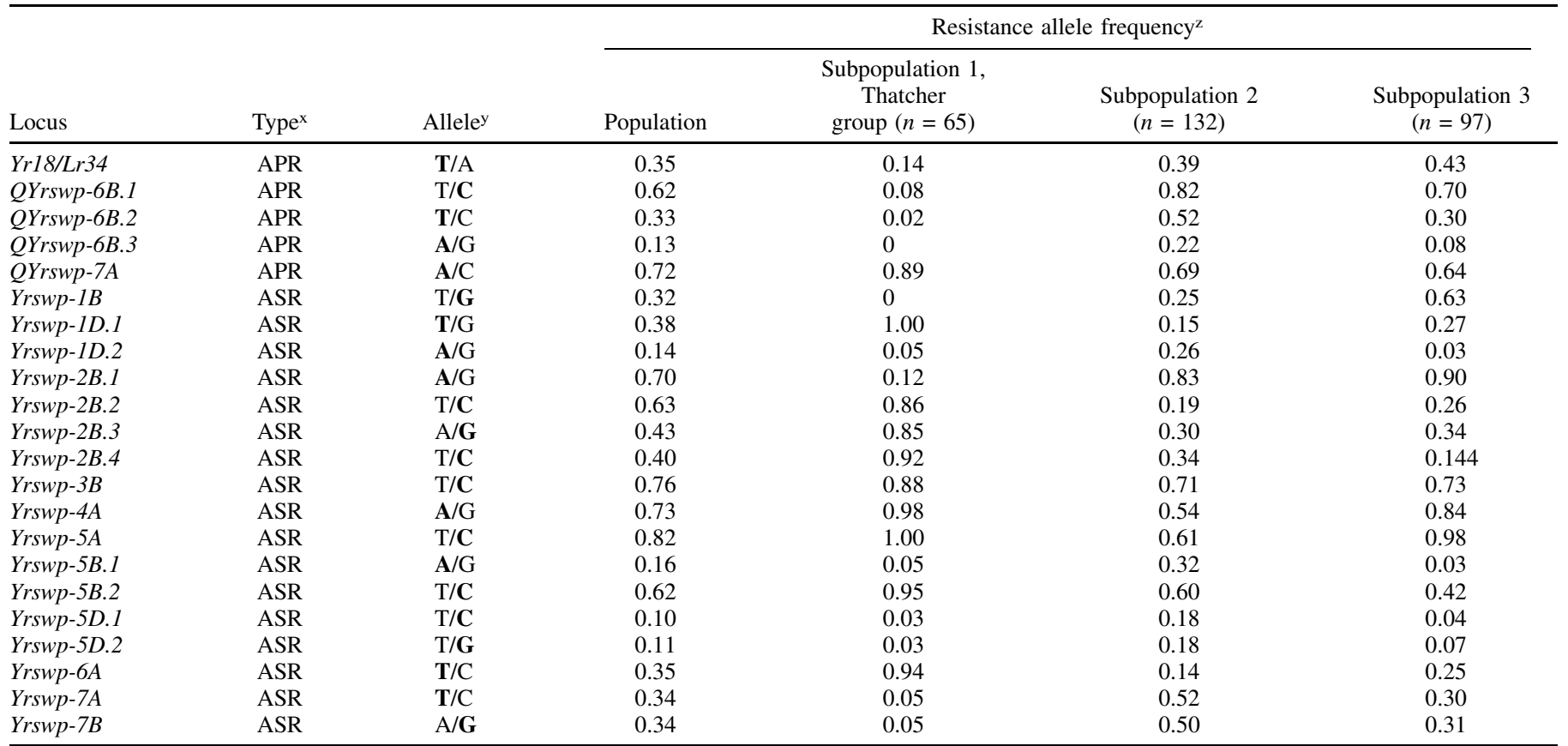

${ }^{x}$ QTL types include adult-plant resistance (APR) and all-stage resistance (ASR).

y The resistance allele for each QTL is bolded.

${ }^{\mathrm{z}}$ Numbers in parentheses are the total numbers of accessions in each subpopulation. 
Center (CIMMYT) and GIZA155 from Egypt in subpopulation 2 contained Yr46/Lr67. Twenty accessions from Argentina, Australia, Colombia, India, Kenya, CIMMYT, the United States, and Uruguay carried the resistance allele of $\mathrm{Yr} 30-\mathrm{Sr} 2-\mathrm{Lr} 27$. These cultivars can serve as direct donors of multiple rust resistance sources in their local wheat breeding programs. It was not unexpected that $35 \%$ of accessions $(n=103)$ had $\operatorname{Yr} 18 / \operatorname{Lr} 34$ in the entire population, because $\operatorname{Yr} 18 / \mathrm{Lr} 34$ has been widely detected in wheat accessions from CIMMYT and many other North American wheat breeding programs (Kolmer et al. 2008). Similar to the GWAS results reported in Gao et al. (2016), we also found that Yr18/Lr34 had highly significant associations to stripe rust resistance in multiple environments at the adult-plant stage in this population, which validated the effectiveness of using the MLM $+K$ model to perform GWAS analysis in our study.

Gao et al. (2016) observed a higher susceptibility against leaf rust in the Thatcher group than the other two groups in field tests, and several leaf rust resistance alleles were almost fixed in the Thatcher group. Similar results were also detected in the present study for stripe rust resistance. We detected that the stripe rust field responses of BLUE_IT and BLUE_SEV of the Thatcher group were significantly higher than the other two subpopulations, and the QYrswp-7A resistance allele for APR was almost fixed in the Thatcher group. Another interesting finding was that the mean seedling IT value tested with PSTV-4 was significantly lower in the Thatcher group than in the other groups, which was probably attributable to the fixation of PSTv-4-associated resistance alleles for Yrswp-2B.2, Yrswp-2B.3, Yrswp-2B.4, Yrswp-4A, and Yrswp$6 A$. Because $89 \%$ of accessions in the Thatcher group were Thatcher-derived NILs that had high genetic similarities with pairwise IBS coefficients ranging from 0.86 to 0.99 , these resistance allele fixations may arise from the common Thatcher background (strong population structure). To test this hypothesis, we removed the 58 Thatcher NILs from this association panel and performed GWAS using the remaining 236 accessions. All significant loci except Yrswp-1D.1 were reidentified, which verified that these loci were indeed significantly associated with the stripe rust resistance.

Based on the wheat consensus map (Wang et al. 2014) and hexaploid wheat integrated maps (Bulli et al. 2016; Maccaferri et al. 2015), we aligned the stripe rust resistance QTL identified in this study with previously published stripe rust resistance genes/QTL. Fourteen QTL overlapped or partially overlapped with previously reported stripe rust genes/QTL. On chromosome 2B proximal to Yrswp-2B.1, three ASR QTL (Yrswp-2B.2, Yrswp-2B.3, and Yrswp-2B.4) that loosely linked with one another ( $\mathrm{LD} r^{2}$ ranging from 0.1 to 0.4 ) were identified to cluster in chromosome 2BL. The three QTL overlapped with previously documented $Y r$ genes $Y r 5, Y r 7, Y r S P, Y r 44$, and $Y r 53$ and were significantly associated with ASR to PSTv-14. None of the three QTL can be either Yr5 or Yr53 because both genes are effective against all U.S. P. striiformis f. sp. tritici races tested (Wan and Chen 2014; Xu et al. 2013). In addition, none of the three QTL can be either $Y r 7$ or $Y r 44$ because they are effective against PSTv-14, whereas both $Y r 7$ and $Y r 44$ are ineffective against this race (Wan and Chen 2014). YrSP could be one of the three chromosome 2B QTL identified in the present study, because it is effective against PSTv-14 and many other races (Feng et al. 2015; Wan and Chen 2014). Further studies are needed to dissect the chromosome $2 \mathrm{~B}$ region harboring multiple genes for stripe rust resistance.

Yrswp-5D.1 and Yrswp-5D.2 were considered as independent ASR QTL because they were loosely linked (LD $\left.r^{2}=0.1\right)$ and located $66 \mathrm{Mb}$ apart on chromosome 5DS. An APR QTL, Yr.caas$5 D S$ jingshuang 16, from Chinese bread wheat cultivar Jingshuang 16 was mapped on the same chromosomal region (Ren et al. 2015). However, Yrswp-5D.1 and Yrswp-5D.2 should be different from the APR QTL because they confer ASR resistance only to PSTV-4.

Six of 21 QTL are most likely to be new QTL because they were located away from the previously reported genes/QTL. The six QTL are Yrswp-1D.1, Yrswp-1D.2, Yrswp-4A, Yrswp-5A, and Yrswp-
5B.2 for ASR and QYrswp-6B.3 for APR to stripe rust. These novel QTL would enrich the wheat gene pool of stripe rust resistance genes and can be rapidly deployed for breeding because they were characterized from cultivars or advanced breeding lines. These donors possessed more improved agronomic traits and less linkage drag than landraces. Except for Yrswp-1D.1 and QYrswp-6B.3, more than one significantly associated SNP was detected for these novel QTL. These molecular markers could help the introgression of stripe rust resistance QTL into wheat cultivars.

\section{ACKNOWLEDGMENTS}

We thank John Kuehner, Wycliffe Nyongesa, and Kent Evans for field management; Victor DeMacon for seed increase in the greenhouse; and Shiaoman Chao for running the Illumina iSelect 90K SNP array.

\section{LITERATURE CITED}

Aktar-Uz-Zaman, M., Tuhina-Khatun, M., Hanafi, M. M., and Sahebi, M. 2017. Genetic analysis of rust resistance genes in global wheat cultivars: An overview. Biotechnol. Biotechnol. Equip. 31:431-445.

Appels, R., Eversole, K., Feuillet, C., Keller, B., Rogers, J., Stein, N., Pozniak, C. J., Choulet, F., Distelfeld, A., Poland, J., et al., International Wheat Genome Sequencing Consortium (IWGSC). 2018. Shifting the limits in wheat research and breeding using a fully annotated reference genome. Science 361:eaar7191.

Bansal, M., Kaur, S., Dhaliwal, H. S., Bains, N. S., Bariana, H. S., Chhuneja, P., and Bansal, U. K. 2016. Mapping of Aegilops umbellulata-derived leaf rust and stripe rust resistance loci in wheat. Plant Pathol. 66:38-44.

Bansal, U., Forrest, K., Hayden, M., Miah, H., Singh, D., and Bariana, H. 2011. Characterisation of a new stripe rust resistance gene $\mathrm{Yr} 47$ and its genetic association with the leaf rust resistance gene Lr52. Theor. Appl. Genet. 122:1461-1466.

Barrett, J. C., Fry, B., Maller, J., and Daly, M. J. 2005. Haploview: Analysis and visualization of LD and haplotype maps. Bioinformatics 21:263-265.

Beddow, J. M., Pardey, P. G., Chai, Y., Hurley, T. M., Kriticos, D. J., Braun, H.-J., Park, R. F., Cuddy, W. S., and Yonow, T. 2015. Research investment implications of shifts in the global geography of wheat stripe rust. Nat. Plants 1:15132.

Bulli, P., Zhang, J., Chao, S., Chen, X., and Pumphrey, M. 2016. Genetic architecture of resistance to stripe rust in a global winter wheat germplasm collection. G3 Genes Genomes Genet. 6:2237-2253.

Case, A. J., Naruoka, Y., Chen, X., Garland-Campbell, K. A., Zemetra, R. S., and Carter, A. H. 2014. Mapping stripe rust resistance in a Brundage $\times$ Coda winter wheat recombinant inbred line population. PLoS One 9:e91758.

Chen, X., Penman, L., Wan, A., and Cheng, P. 2010. Virulence races of Puccinia striiformis f. sp. tritici in 2006 and 2007 and development of wheat stripe rust and distributions, dynamics, and evolutionary relationships of races from 2000 to 2007 in the United States. Can. J. Plant Pathol. 32:315-333.

Dadkhodaie, N., Karaoglou, H., Wellings, C., and Park, R. 2011. Mapping genes Lr53 and Yr35 on the short arm of chromosome 6B of common wheat with microsatellite markers and studies of their association with Lr36. Theor. Appl. Genet. 122:479-487.

Draz, I. S., Abou-Elseoud, M. S., Kamara, A.-E. M., Alaa-Eldein, O. A.-E., and El-Bebany, A. F. 2015. Screening of wheat genotypes for leaf rust resistance along with grain yield. Ann. Agric. Sci. 60:29-39.

Ellis, J. G., Lagudah, E. S., Spielmeyer, W., and Dodds, P. N. 2014. The past, present and future of breeding rust resistant wheat. Front. Plant Sci. 5:641.

Evanno, G., Regnaut, S., and Goudet, J. 2005. Detecting the number of clusters of individuals using the software STRUCTURE: A simulation study. Mol. Ecol. 14:2611-2620.

Falush, D., Stephens, M., and Pritchard, J. K. 2003. Inference of population structure using multilocus genotype data: Linked loci and correlated allele frequencies. Genetics 164:1567-1587.

Feng, J. Y., Wang, M. N., Chen, X. M., See, D. R., Zheng, Y. L., Chao, S. M., and Wan, A. M. 2015. Molecular mapping of YrSP and its relationship with other genes for stripe rust resistance in wheat chromosome 2BL. Phytopathology 105:1206-1213.

Food and Agriculture Organization of the United Nations. 2019. FAO Cereal Supply and Demand Brief. http://www.fao.org/worldfoodsituation/csdb/en/

Gao, L., Turner, M. K., Chao, S., Kolmer, J., and Anderson, J. A. 2016. Genome wide association study of seedling and adult plant leaf rust resistance in elite spring wheat breeding lines. PLoS One 11:e0148671.

Hao, Y., Chen, Z., Wang, Y., Bland, D., Buck, J., Brown-Guedira, G., and Johnson, J. 2011. Characterization of a major QTL for adult plant resistance to stripe rust in US soft red winter wheat. Theor. Appl. Genet. 123:1401-1411. 
Hao, Z., Lv, D., Ge, Y., Shi, J., Yu, G., Chen, J. 2018. RIdeogram: Drawing SVG graphics to visualize and map genome-wide data in idiograms. $\mathrm{R}$ package version 0.1.0. $\mathrm{R}$ Foundation for Statistical Computing, Vienna, Austria.

Helguera, M., Khan, I., Kolmer, J., Lijavetzky, D., Zhong-Qi, L., and Dubcovsky, J. 2003. PCR assays for the Lr37-Yr17-Sr38 cluster of rust resistance genes and their use to develop isogenic hard red spring wheat lines. Crop Sci. 43:1839-1847.

Herrera-Foessel, S. A., Singh, R. P., Lillemo, M., Huerta-Espino, J., Bhavani, S., Singh, S., Lan, C., Calvo-Salazar, V., and Lagudah, E. S. 2014. Lr67/ Yr46 confers adult plant resistance to stem rust and powdery mildew in wheat. Theor. Appl. Genet. 127:781-789.

Huerta-Espino, J., Singh, R., German, S., McCallum, B., Park, R., Chen, W. Q., Bhardwaj, S., and Goyeau, H. 2011. Global status of wheat leaf rust caused by Puccinia triticina. Euphytica 179:143-160.

International Maize and Wheat Improvement Center. 2015. Wheat: The vital grain of civilization and food security. https://www.slideshare.net/CIMMYT/wheat-43958418

Kolmer, J. A., Singh, R. P., Garvin, D. F., Viccars, L., William, H. M., Huerta-Espino, J., Ogbonnaya, F. C., Raman, H., Orford, S., Bariana, H. S., and Lagudah, E. S. 2008. Analysis of the Lr34/Yr18 rust resistance region in wheat germplasm. Crop Sci. 48:1841-1852.

Krattinger, S. G., Lagudah, E. S., Spielmeyer, W., Singh, R. P., Huerta-Espino, J., McFadden, H., Bossolini, E., Selter, L. L., and Keller, B. 2009. A putative ABC transporter confers durable resistance to multiple fungal pathogens in wheat. Science 323:1360-1363.

Kuraparthy, V., Chhuneja, P., Dhaliwal, H. S., Kaur, S., Bowden, R. L., and Gill, B. S. 2007. Characterization and mapping of cryptic alien introgression from Aegilops geniculata with new leaf rust and stripe rust resistance genes Lr57 and $Y r 40$ in wheat. Theor. Appl. Genet. 114:1379-1389.

Lin, F., and Chen, X. 2007. Genetics and molecular mapping of genes for racespecific all-stage resistance and non-race-specific high-temperature adultplant resistance to stripe rust in spring wheat cultivar Alpowa. Theor. Appl. Genet. 114:1277-1287.

Line, R. F., and Qayoum, A. 1992. Virulence, aggressiveness, evolution and distribution of races of Puccinia striiformis (the cause of stripe rust of wheat) in North America, 1968-87. U.S. Dept. Agric. Tech. Bull. 1788

Lipka, A. E., Tian, F., Wang, Q., Peiffer, J., Li, M., Bradbury, P. J., Gore, M. A., Buckler, E. S., and Zhang, Z. 2012. GAPIT: Genome association and prediction integrated tool. Bioinformatics 28:2397-2399.

Liu, W., Maccaferri, M., Bulli, P., Rynearson, S., Tuberosa, R., Chen, X., and Pumphrey, M. 2017a. Genome-wide association mapping for seedling and field resistance to Puccinia striiformis f. sp. tritici in elite durum wheat. Theor. Appl. Genet. 130:649-667.

Liu, W., Maccaferri, M., Chen, X., Laghetti, G., Pignone, D., Pumphrey, M., and Tuberosa, R. 2017b. Genome-wide association mapping reveals a rich genetic architecture of stripe rust resistance loci in emmer wheat (Triticum turgidum ssp. dicoccum). Theor. Appl. Genet. 130:2249-2270.

Liu, W., Maccaferri, M., Rynearson, S., Letta, T., Zegeye, H., Tuberosa, R., Chen, X., and Pumphrey, M. 2017c. Novel sources of stripe rust resistance identified by genome-wide association mapping in Ethiopian durum wheat (Triticum turgidum ssp. durum). Front. Plant Sci. 8:774

Liu, W., Naruoka, Y., Miller, K., Graland-Campbell, K. A., and Cater, H. A. $2017 \mathrm{~d}$. Characterizing and validating stripe rust resistance loci in US Pacific Northwest winter wheat accessions (Triticum aestivum L.) by genomewide association and linkage mapping. Plant Genome 11:170087.

Maccaferri, M., Zhang, J., Bulli, P., Abate, Z., Chao, S., Cantu, D., Bossolini, E., Chen, X., Pumphrey, M., and Dubcovsky, J. 2015. A genome-wide association study of resistance to stripe rust (Puccinia striiformis $\mathrm{f}$. $\mathrm{sp}$. tritici) in a worldwide collection of hexaploid spring wheat (Triticum aestivum L.). G3 Genes Genomes Genet. 20:449-465.

Mago, R., Tabe, L., McIntosh, R., Pretorius, Z., Kota, R., Paux, E., Wicker, T., Breen, J., Lagudah, E., and Ellis, J. 2011. A multiple resistance locus on chromosome arm 3BS in wheat confers resistance to stem rust $(\mathrm{Sr} 2)$, leaf rust ( $L r 27)$ and powdery mildew. Theor. Appl. Genet. 123:615-623.

Marais, F., Marais, A., McCallum, B., and Pretorius, Z. 2009. Transfer of leaf rust and stripe rust resistance genes Lr62 and Yr42 from Aegilops neglecta Req. ex Bertol. to common wheat. Crop Sci. 49:871-879.

Marais, G., McCallum, B., Snyman, J., Pretorius, Z., and Marais, A. 2005. Leaf rust and stripe rust resistance genes Lr54 and Yr37 transferred to wheat from Aegilops kotschyi. Plant Breed. 124:538-541.

Marais, G. F., McCallum, B., and Marais, A. 2006. Leaf rust and stripe rust resistance genes derived from Aegilops sharonensis. Euphytica 149:373-380.

McGrann, G. R. D., Smith, P. H., Burt, C., Mateos, G. R., Chama, T. N., MacCormack, R., Wessels, E., Agenbag, G., and Boyd, L. A. 2014. Genomic and genetic analysis of the wheat race-specific yellow rust resistance gene Yr5. J. Plant Sci. Mol. Breed. 3:2.

Mcintosh, R. A., Dubcovsky, J., Rogers, W. J., Morris, C., Appels, R., and Xia, X. C. 2014. Catalogue of Gene Symbols for Wheat: 2013-2014
Supplement. Komugi- Wheat Genetic Resources Database. http://www. shigen.nig.ac.jp/wheat/komugi/

Naruoka, Y., Garland-Campbell, K., and Carter, A. 2015. Genome-wide association mapping for stripe rust (Puccinia striiformis $\mathrm{f}$. sp. tritici) in US Pacific Northwest winter wheat (Triticum aestivum L.). Theor. Appl. Genet. 128:1083-1101.

Peterson, R. F., Campbell, A., and Hannah, A. 1948. A diagrammatic scale for estimating rust intensity on leaves and stems of cereals. Can. J. Res. 26c: 496-500.

Piepho, H.-P., and Möhring, J. 2007. Computing heritability and selection response from unbalanced plant breeding trials. Genetics 177:1881-1888.

Prins, R., Pretorius, Z. A., Bender, C. M., and Lehmensiek, A. 2011. QTL mapping of stripe, leaf and stem rust resistance genes in a Kariega $\times$ Avocet S doubled haploid wheat population. Mol. Breed. 27:259-270.

Pritchard, J. K., Stephens, M., and Donnelly, P. 2000. Inference of population structure using multilocus genotype data. Genetics 155:945-959.

Qureshi, N., Bariana, H., Forrest, K., Hayden, M., Keller, B., Wicker, T., Faris, J., Salina, E., and Bansal, U. 2017. Fine mapping of the chromosome 5B region carrying closely linked rust resistance genes $\mathrm{Yr} 47$ and $L r 52$ in wheat. Theor. Appl. Genet. 130:495-504.

Ren, Y., Li, Z., He, Z., Wu, L., Bai, B., Lan, C., Wang, C., Zhou, G., Zhu, H., and Xia, X. 2012. QTL mapping of adult-plant resistances to stripe rust and leaf rust in Chinese wheat cultivar Bainong 64. Theor. Appl. Genet. 125:1253-1262.

Ren, Y., Liu, L. S., He, Z. H., Wu, L., Bai, B., and Xia, X. C. 2015. QTL mapping of adult-plant resistance to stripe rust in a 'Lumai $21 \times$ Jingshuang 16' wheat population. Plant Breed. 134:501-507.

Riethmüller, A., Voglmayr, H., Goker, M., Weiss, M., and Oberwinkler, F. 2002. Phylogenetic relationships of the downy mildews (Peronosporales) and related groups based on nuclear large subunit ribosomal DNA sequences. Mycologia 94:834-849.

Santra, D., Chen, X., Santra, M., Campbell, K., and Kidwell, K. 2008. Identification and mapping QTL for high-temperature adult-plant resistance to stripe rust in winter wheat (Triticum aestivum L.) cultivar 'Stephens'. Theor. Appl. Genet. 117:793-802.

Singh, R. P., Huerta-Espino, J., and William, M. 2001. Slow rusting genes based resistance to leaf and yellow rusts in wheat: Genetics and breeding at CIMMYT. Pages 103-108 in: Proc. 10th Assembly of the Wheat Breeding Soc. Australia, Mildura, Australia. Wheat Breeding Society of Australia Inc., Australia.

Singh, R., Nelson, J., and Sorrells, M. 2000. Mapping Yr28 and other genes for resistance to stripe rust in wheat. Crop Sci. 40:1148-1155.

Singh, R. P., Singh, P. K., Rutkoski, J., Hodson, D. P., He, X., Jørgenssen, L. N., Hovmøller, M. S., and Huerta-Espino, J. 2016. Disease impact on wheat yield potential and prospects of genetic control. Annu. Rev. Phytopathol. 54:303-322.

Suenaga, K., Singh, R., Huerta-Espino, J., and William, H. 2003. Microsatellite markers for genes $\operatorname{Lr34/Yr18}$ and other quantitative trait loci for leaf rust and stripe rust resistance in bread wheat. Phytopathology 93:881-890.

Tiwari, S., Tomar, R., Chand, S., and Singh, N. 2014. Combining multiple rust resistance genes by phenotypic and marker assisted selection in wheat (Triticum aestivum L.). Indian J. Genet. Plant Breed. 74:181-188.

Wan, A., and Chen, X. 2014. Virulence characterization of Puccinia striiformis f. sp. tritici using a new set of $Y r$ single-gene line differentials in the United States in 2010. Plant Dis. 98:1534-1542.

Wang, S., Wong, D., Forrest, K., Allen, A., Chao, S., Huang, B. E., Maccaferri, M., Salvi, S., Milner, S. G., and Cattivelli, L. 2014. Characterization of polyploid wheat genomic diversity using a high-density 90000 single nucleotide polymorphism array. Plant Biotechnol. J. 12:787-796.

William, M., Singh, R., Huerta-Espino, J., Islas, S. O., and Hoisington, D. 2003. Molecular marker mapping of leaf rust resistance gene $\mathrm{Lr} 46$ and its association with stripe rust resistance gene $Y r 29$ in wheat. Phytopathology 93:153-159.

Wolfinger, R., Federer, W. T., and Cordero-Brana, O. 1997. Recovering information in augmented designs, using SAS PROC GLM and PROC MIXED. Agron. J. 89:856-859.

Xu, L., Wang, M., Cheng, P., Kang, Z., Hulbert, S., and Chen, X. 2013. Molecular mapping of $\mathrm{Yr} 53$, a new gene for stripe rust resistance in durum wheat accession PI 480148 and its transfer to common wheat. Theor. Appl. Genet. 126:523-533.

Zadoks, J. C., Chang, T. T., and Konzak, C. F. 1974. A decimal code for the growth stages of cereals. Weed Res. 14:415-421.

Zegeye, H., Rasheed, A., Makdis, F., Badebo, A., and Ogbonnaya, F. C. 2014. Genome-wide association, mapping for seedling and adult plant resistance to stripe rust in synthetic hexaploid wheat. PLoS One 9:e105593.

Zhou, X., Wang, W., Wang, L., Hou, D., Jing, J., Wang, Y., Xu, Z., Yao, Q., Yin, J., and Ma, D. 2011. Genetics and molecular mapping of genes for high-temperature resistance to stripe rust in wheat cultivar Xiaoyan 54. Theor. Appl. Genet. 123:431-438. 